\title{
Tombs and Reels of Consciousness: The aesthetics that interlink ancient ritualistic artefacts and digital, augmented and virtual reality
}

\author{
Lila Moore \\ Cybernetic Futures Inst. \\ Dingley Place, London, UK \\ Info@cyberneticinstitute.com
}

\begin{abstract}
In 1945 the filmmaker Maya Deren sent a scenario to the Metropolitan Museum of Art in New York with a proposal to make a $16 \mathrm{~mm}$ film on the ancient Egyptian tomb of Perneb. In the proposal she emphasises the difficulty, which the topic of ancient Egypt poses to viewers in terms of their ability to identify with a culture whose ideology is so different from their own. Deren devises a strategy akin to racial memory with which to meaningfully reconstruct the life of the tomb's deceased dweller. An analysis of her ideas firstly demonstrates how she plans to utilise the cinematic apparatus in conceptual affinity with the ancient Egyptian belief thereby offering the viewers a participatory and apparitional experience in archaic consciousness of eternal life, whilst following the narrative of the man whose spirit inhabits the tomb. Secondly, Deren explicates that archaic rituals and modern technologies are both time-based and relativistic. Indeed, augmented reality and virtual reality can be employed to manipulate and transfigure our perception of, and position in, space-time. Technoetic sensibility is accordingly applied to theoretically visualise the tomb as a digitally enhanced time-machine and as apparitional, participatory, as well as enlightening, encounter with a remote culture.
\end{abstract}

Tomb of Perneb. Maya Deren. Virtual reality. Technoetic arts. Consciousness. Apparition. Ritual. Museums.

\section{INTRODUCTION}

In May 1945, the filmmaker Maya Deren sent a scenario to the Metropolitan Museum of Art in New York with a proposal to make a $16 \mathrm{~mm}$ film on the ancient Egyptian tomb of Perneb (Clark et al. 1988, pp.294-295), one of the highlights of the museum's Egyptian collection. Although the film was not realised, the scenario's concepts illuminate the significant challenges involved in contemporary exhibits of ancient artefacts and monuments. In particular, Deren discusses the difficulty, which the topic of ancient Egypt poses to viewers in terms of their ability to identify with a culture whose ideology is so different from their own.

Prior to addressing the merit of her argument in detail, it is relevant to note that encounters with ancient cultures in museum settings apparently involve a sense of alienation or panic. The artist Sarah Sze (2015) observes that visitors to the tomb of Perneb often leave the interior in haste, a reoccurring behavioural pattern documented in her video. Furthermore, museums' artefacts including ancient tombs already exist in a state of augmented reality. Immersed in foreign environments, they become perplexing relics lost in time and space. Even on their native historical grounds they are nowadays embedded within touristic framework that may induce subliminal friction not only with their initial purpose but also with the mind-set that designed them. Ancient Egyptian tombs were not mere aesthetic designs or visualisations of abstract metaphysical ideas. They were raised as architectonic structures and technologies that served the dead and the living in both pragmatic and ritualistic ways. Therefore, the sign 'do not touch' and the rope that signifies to keep distance from artefacts in museum settings, on one hand, amplify the visitors' feeling of estrangement from the objects and on the other hand, impose artificial boundaries, which according to Tucker (1992, p.1) contrast the shape-shifting and participatory realms of shamanic and animistic cultures. In principle, the 
technologies of augmented reality (AR) and virtual reality (VR) can bypass these physical boundaries including the restrictions that they impose by allowing the visitors the capacity to interact with the artefacts in various intangible, immersive modes.

To demonstrate the aesthetics that interlinks ancient magical, shamanic ritual and digital technologies, I first analyse the manners with which Deren plans to allow the film viewers' sympathetic access to the racial memory that restores the narrative of the man whose spirit inhabits the tomb. It involves a reflection on her poetic visualisations that aim to harness the cinematic apparatus in conceptual affinity with the ancient Egyptian worldview. Deren explicates that archaic rituals and modern technologies are time-based and relativistic. Indeed, both augmented reality and virtual reality can be utilised to manipulate and transfigure our perception of and position in spacetime. Moreover, these technologies induce multifaceted environments, which as I demonstrate, correlate with the archaic reality of Perneb's world as well as similar relics and shrines. Secondly, Deren's notions of racial memory and ritualistic aesthetics are discussed in relation to technoetic sensibility. The latter is applied to theoretically formulate the ancient tomb as a digitally enhanced time-machine and a portal of ritual and double consciousness that generate apparitional and participatory happenings. Finally, I propose that a thoughtful application of augmented reality and virtual reality may enable the visitors an interaction with, and participation in, a shared narrative with a remote culture by opening the encounter to deeper layers of consciousness beyond the purely temporal or historical experience of the monument.

\section{CONVERSATION WITH FORGOTTEN CIVILISATION THROUGH CINEMATIC AESTHETICS}

Death is generally perceived by Western societies as a gloomy affair involving a lingering fear of the unknown. In ancient Egypt, separation from existence was not as clear-cut and communication with the dead continued beyond life. The contrast between the modern Westerns' and the ancient Egyptians' attitudes to death prompts Deren to suggest a film project that could reconcile the gap between two different cultural ideologies. The film would provide the visitors to the museum empathic and educational access to the life of the tomb's original occupant. Considering the fact that even today some visitors to the tomb of Perneb seem to be somewhat agitated by its surroundings (Sze 2015), revisiting Deren's ideas could provide further insight to visitors' reactions and expectations and possibly lead to informed solutions or additional creative options with the support of new technologies.

Deren asserts that the 20-minute film should convey and obey the logic of the ancient Egyptian culture. To respect the latter's integrity, we need to overcome our sense of separation; the fact that the ancient Egyptians are dissimilar to us should not obstruct meaningful contact with them. Hence, she proposes a strategy she terms as racial memory with the film functioning as the realisation of the act of racial memory (Clark et al. 1988, pp.294-295). Recovering racial memory is for Deren a process akin to suddenly remembering a grandfather or perhaps a great-grandmother. First there is a somewhat vague image in a characteristic pose then one begins to recollect familiar objects he or she used to handle, like a pipe or pan, or certain emotions, smells or even tastes and more, that were associated with them. By envisioning and regarding the ancient Egyptians as our ancestors, we can form 'familial bond' that will 'simulate sympathetic, active desire to understand them rather than to be casually curious about this exotic, mythological race, with its strange ways' (lbid. p.295.).

For this purpose, Deren suggests an aesthetic sensibility that would transform the film camera into an instrument that probes not only the mazes of the tomb but also simultaneously the mazes of our consciousness as we begin to scan our memories. The tomb's tunnels, which sometimes induce neurotic or fearful responses in visitors, would turn, with the travelling camera, into intimate quasineurological pathways leading to their own quasimythic memories. When the camera arrives at the human figure, the latter is intercut by an image of a bright eye (presumably the eye of Horus) that according to Deren symbolises resurrection. In fact, the eye of Horus was a major funerary amulet against darkness and death, an archetype of the victory of light and cosmic order (Maravelia 2017).

Images of symbolic eyes appear in other films by Deren. In Meshes of the Afternoon (1943), the protagonist's eye is interchanged with the camera lens. Here, both the camera as an instrument of modern technology and the ancient magical Egyptian eye function together as one apparatus to reveal the man in his home. Deren's description is subtly merging the magical reality of the man's tomb as his home for the viewers/visitors as well as readjusting their comprehension of the tomb not as a dreary grave but as an engaging domestic setting albeit in another dimension of space-time. Clearly, Deren is aware of the Western tendency to attempt to manage the ancient culture instead of cultivating a conversation with its worldview (Tucker 1992). Once revealed, the man, according to Deren's scenario, speaks to us about various things, 
grounding a large portion of his commentary on ancient Egyptian writings.

Contemporary viewers could certainly entertain a correspondence with a distant ancestor who relates his stories as if they were shared memories. Interestingly, the custom of exchanging letters with the deceased was common in Ancient Egypt where, for example, a deceased father continued advising his sons, who collected his letters from his tomb (Simpson \& Ritner 2003). Regardless of the sources that informed Deren's scenario, the cinematic strategy and its associated aesthetics invite the film viewers and the visitors to the tomb to abandon for 20 minutes their worldview concerning temporal time, life and death, and become immersed in the encounter not by 'seeing something new' but by recovering the sense of remembering 'something known but forgotten' (Clark et al. 1988, p.295).

In writings from the same period, Deren speculates about a mode of death by amnesia, involving total loss of recollection and identity. Her poem 'Death by Amnesia' written in 1942 is based on a newspaper story about a twenty-six-year-old mildmannered man who was taken to a missing person bureau because he approached an officer in the street and asked him: 'Can you tell me who I am?' The homicide detectives who questioned him were unable to retrieve his identity (Ibid. p.66). Deren utilises the poem as means to reconstruct the lost person through the ancient Egyptian model of a human being composed of a corruptible frame and five indestructible and independent nonphysical bodies.

According to Geis (2013) Deren's scenario and poem reflect the myth of Osiris, which is a reoccurring theme in Deren's body of works. In the myth of Isis and Osiris, the goddess resurrects her consort by collecting the scattered members of his mutilated body. Interestingly, Deren's scenario seems to appropriately engage with the aesthetics of cinema as means to demonstrate the mythic and ritualistic aspects of the theme of racial memory. In order to remember the deceased as an individual who once lived, the fragmented recollections that constitute his life and identity are gathered and rearranged. The process, on one hand, mirrors the splicing and piecing together of a film through editing and on the other hand, could be metaphorically compared to Isis meticulously marrying the dismembered body of Osiris, thus remembering and resurrecting him. The viewers as well become participants in the process of reconstructing the identity and life of the original tomb owner, whilst immersed in a mythic perception of the resurrection of his identity in the tomb, a space-time of eternal life.

\section{THE RITUALISTIC TECHNOETIC FORM IN ART}

The ritualistic form in art is a term coined by Deren and theorised in her manuscript An Anagram of Ideas on Art, Form and Film (1946). Art and ritual share similar functions, she states, as 'they both conspire to cause an effect in others by triggering a process that at best generates new knowledge and transformation in perception or comprehension' (Moore 2018a, p.124). However, the roles of the artist and shaman have ceased to be interchangeable as advances in science and technology have modified the traditional role of shamans who used to possess all the knowledge required for life and living in a world in which art was part of a ritualistic and magical system with destructive, restoring and healing powers. A technologically and scientifically informed ritualistic art, Deren argues, 'is capable of drawing on, and assimilating, the blueprint of archaic shamanic and magical rituals' (Ibid.). The ritualistic form acts directly on its target and induces impact as effectively as the induction of pain or whatever is its emotional or intellectual intent. Deren (1946, p.17) conceives it as a calculative intentional method, which is above all an exercise of consciousness. This mode of ritualistic art could be compared to the operation of a magical thought-form, a noetic essence or immaterial intentional data that is encapsulated in, and drives its effectiveness from, the technological and aesthetic design that carries it. Essentially, this ritualistic art form is technoetic, a term coined by the British artist and theorist Roy Ascott, and pertains to combinations of tech and nous, that is, technology and mind.

Broadly, in Greek philosophy (...) the nous pertains to a deeply intuitive intellectual apprehension of first principles and truths. It is also a metaphysical and theological state of thought referred to as the active intellect of the gods and the divine. Technoetic aesthetics bypasses the surface image of the world and allows an interpretive creative process that considers the interrelations of technology and mind including their various religious and spiritual contexts. (Moore 2018b, p.2)

The ritualistic technoetic art form that I propose merges the key principles of Deren's ritualistic art form and Ascott's technoetic art for the purpose of exploring and exhibiting archaic ritualistic and magical structures, practices and states of consciousness through ancient and contemporary settings, techniques and technologies. 


\section{THE TOMB OF PERNEB AS TECHNOETIC TIME-MACHINE}

In order to formulate the tomb as a technoetic timemachine, I superimpose technoetic sensibility over Deren's original scenario. The creative research process, theoretically employed here, involves visualising the integration of augmented reality and virtual reality within the scenario's framework. The tomb of Perneb is an impressive building, which in the museum setting exerts an authentically solemn atmosphere, especially by allowing the visitors a kinetic experience of its space and passages.

In thinking of incorporating VR into the current experience, it is useful to refer to projects such as Nefertari: Journey to Eternity or Tombs and Monuments of Egypt (2018) that utilise VR and $360^{\circ}$ video to offer pristine virtual access to similar monuments. However, Deren's scenario, likewise technoetic awareness, does not engage with the surface image of the tomb but seeks a profounder interpretation of the encounter with it and in particular with its owner. Intriguingly, Perneb's burial chamber, which was located below ground, remained in Egypt, whilst the public area of his tomb's above-ground structure was installed in the Metropolitan Museum of Art over a century ago. (The history of the tomb is detailed in a documentary by the Metropolitan Museum of Art, directed and produced by Noey 2011).

Perhaps similarly to the young man of Deren's poem who lost his identity, Perneb's spiritual identity is forgotten somewhere in between ancient Egypt and modern New York. The former, walking down Broadway was seen dressed in contemporary clothes, though no one noticed his bare feet because they were coated with the mud of the Nile that only he remembered. Remembering Perneb, in accordance with Deren's concept, involves returning to Egypt by forming a virtual tunnel in space-time that connects the lower and upper parts of the tomb thereby intermingling the past, present, temporal and eternal time. Broadly, the metaphoric and aesthetic notion of the tomb as a time-machine correlates with, and aims to convey the ancient Egyptian mythic perception of the tomb as a sacred space that miraculously unifies temporal and infinite time and space.

According to Maravelia (2003), the tomb was regarded as a virtual cosmic birth chamber for eternity. It manifested a multifaceted understanding of time, cyclic and continuum. I thereby propose to visualise the tomb as a technoetic time-machine equipped with VR and AR capacities, which are not specifically detailed but described in terms of their general potentials and their ability to creatively manipulate and explore space and time. The tomb in the museum is framed in the present as a concrete archaic structure.

Following Deren's suggestion, the man in the tomb is gradually revealed through recollections. These are images and sensations that emerge from a shared stream of memories and there could be a number of strategies to make them appeal to the visitor in an interpersonal way. One example is via VR leading the visitor to the man's table on which a letter was left addressed to the one who found it as a distant relative. Most importantly, however, is to introduce the visitor to the multifaceted type of consciousness that the tomb involves and which reflects both the Egyptian model of identity and death as birth in eternal life.

In the tomb (Simpson \& Ritner 2003), the realm of its dweller and his presence in it are the manifestation of his spiritual double (the $\mathrm{ka}$ ) that has survived after the death of his physical body. Drawings and all other images including his statue are not portrayals of him but of his ka, which, beyond reach to mortals, also inhabits his statue. These details are relevant because depictions of the man in the tomb that are in affinity with his cultural and religious context involve the design of overlapping realities. It is a state akin to double consciousness that refers to simultaneously experiencing more than one place and time where two or more realities intersect.

Technically and aesthetically, VR incorporated in the actual setting of the tomb could generate in the visitor an awareness of double consciousness by amplifying the state of being both in the actual tomb as well as within its owner's spiritual environment. The tomb would be experienced as comprising from both actual locale with an added metaphysical dimension. The focal point of such an interaction could be effective at the false door of the tomb, which was a central feature for the Egyptians, reminding them of the difference between and separation of the corporeal and the spiritual life.

It was only the deceased's ka, who, as an intangible double, could pass through the tomb's false door and all other walls. As noted, the current tomb of Perneb does not include a burial chamber and as a result its owner's ka is denied access to the public chapel. The latter's religious-magical function was to endue him with life-force whilst protecting and sustaining his perpetual existence beyond the temporal dimension. In such cases, the deceased may resort to other forms of magic. However, the situation allows educational and imaginative approaches to the scenario by utilising the false door of the tomb as a starting point. (Figure 1) From the false door via VR video, for example, the visitor would be transported into a cosmic tunnel reeling in the Milky Way. The tunnel 
would reconnect the deceased's ka and his burial chamber with the tomb whilst offering the visitor insight to the Egyptian expression of infinite spacetime. Aided by the light of the rising sun, delivered by the mother goddess Nut of the infinite cosmos, the ka will find his way back to his earthly-spiritual abode.

Back in the tomb, AR could be added to the visitor's experience to demonstrate the life-force that sustains the ka. The life-force emanates from the offerings given to the ka seen in the decorative drawings of scenes depicting abundance and plenty of delicious foods. These were displayed on the walls of the public area of the tomb along with fresh nourishments that were left by relatives and priests. The life-force that sustained the ka was perceived as the metaphysical substance of the physical offerings, subjects and objects. Through the use of $A R$, the notion of a life-force could manifest as a celebration of joyful colours and sounds that may envelop the public area of the tomb and with which the visitors could playfully interact. Such an experience would rekindle the ceremonial function and spiritual life of the tomb and the zest of the hopeful social, participatory and familial rites that it held. Consequently, the tomb becomes multi-dimensional and allows further elaborations of its owner's narrative. Based on Egyptian lore, the ka could be comprehended as an apparitional being, which is part of a collection of spiritual bodies that the individual is made of. It lives in a tomb, which constitutes a gateway to the cosmos, reeling in space-time to the rhythms of daily cycles. The tomb and its owner may be realised as a constellation of states of consciousness manifesting as moral qualities instead of physical figures or particular actions. The visual and sensorial immersive qualities that $A R$ and VR can in principle produce resonate with the multi-layered and utterly immersive quality of the tomb's practical-magical configuration and the apparitional and multi-faceted composition of its original owner.

\section{THE TECHNOLOGIES AND AESTHETICS OF RITUALISTIC AND DOUBLE CONSCIOUSNESS}

Maravelia (2003) explicates that the ancient Egyptians were not concerned with pure science nor shared our rational preoccupation with mathematical knowledge. Their religious daily reality was ritualistically orientated and magical in nature. Although they were not a tribal society, their magical thinking and behaviour had shamanic and animistic tendencies. The tomb of Perneb has therefore provided a compact model with which to explore the somewhat syncretic interrelations between the ancient Egyptian magical techniques and technologies and current VR and $A R$ technologies.

It is an investigation that closely relates to my ongoing practice-based research. I observe (Moore $2018 a$, p.119) in a different article the 'pivotal potentials that lurk in the untapped, infinite and occasionally transcendent dimensions that advanced technologies generate, often as a byproduct of their pragmatic and commercial applications.' I refer to Ascott (2003) to establish my proposition about the techno-spiritual and scientific character of the next momentum of the spiritual in art in the twenty-first century. Ascott highlights (Ibid. 357.) the shamanic sensibility of 'double consciousness' 'which seems to parallel our interaction with cybernetic and telematic systems, cyborg entities and $\mathrm{Al}$, and immersion in virtual and augmented realities' (Moore 2018a, p.119). Ascott defines 'double consciousness' as:

The state of being that gives access, at one and the same time, to two distinctly different fields of experience: psychic space and cyberspace, the material world and the virtual, in an artwork and outside of it. (2003, p.377)

This intriguing state of consciousness has occupied the trajectory of my creative practice and theoretical ideas and has involved the different relationships that transpire between the physical and apparitional body and mind and the screen, as well as body-mind interrelations in cyberspace, virtual and augmented reality. I tend to observe these interactions in choreographic terms that consider the aspects of movement in space and time.

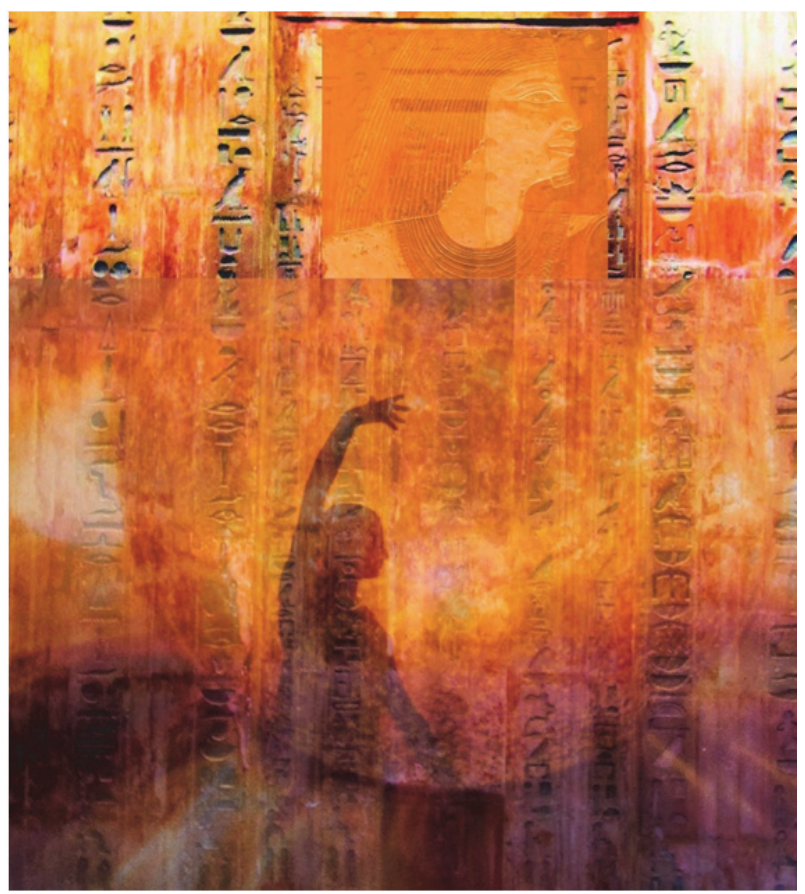

Figure 1: Visualisation of the False Door as VR video. 


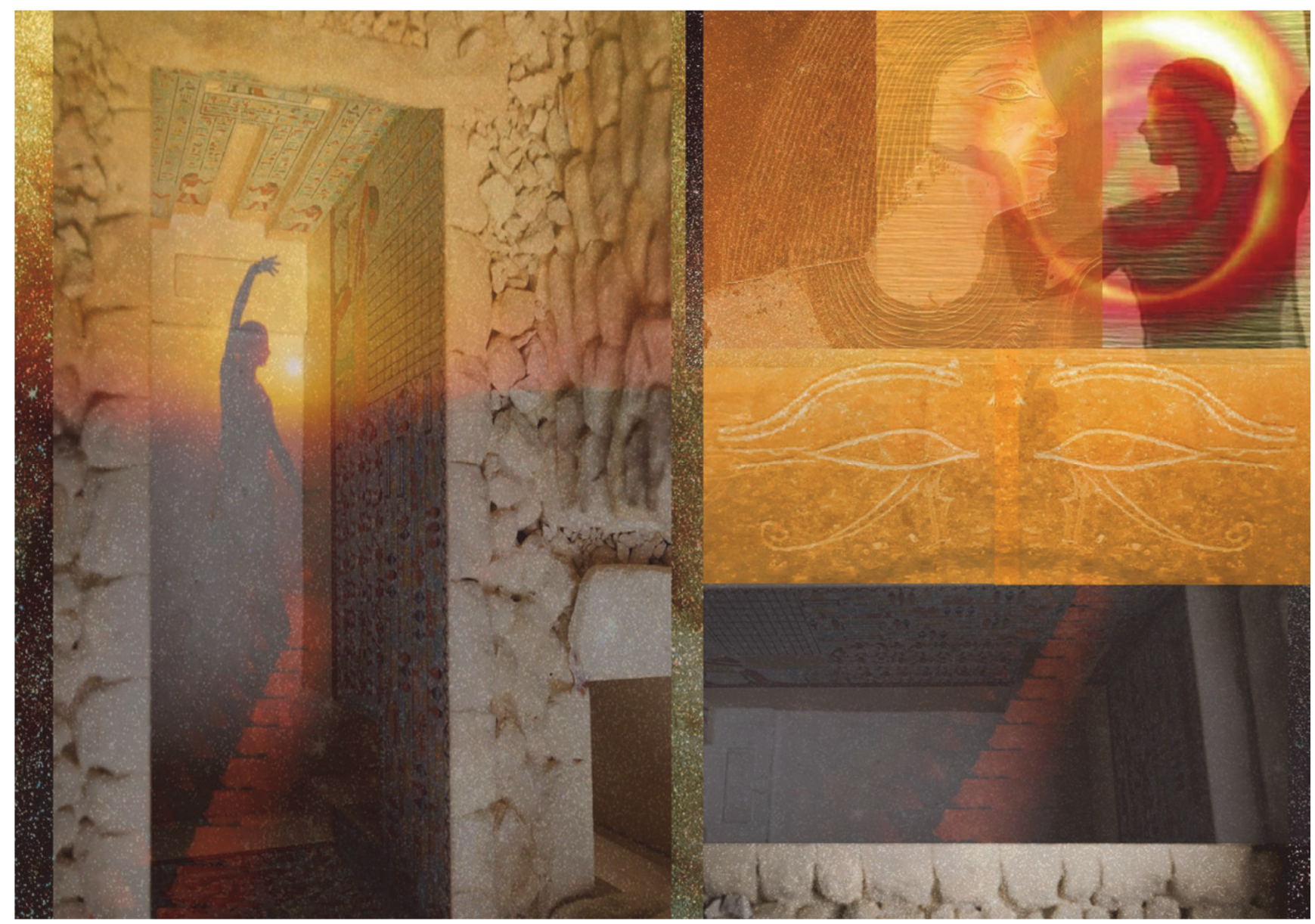

Figure 2: Dance of the Mind, Choreographical Visualisations of Space-Time in the Cosmic Tomb.

Deren's filmic sensibility is rooted in time and motion as well. Visualising the encounter in the tomb as a dance or movement-based performance generates an intricate set of relations between the user of the VR technology and the apparitional presence and his movements in that environment. The VR experience locates the user within the apparitional space-time similarly to the experience of the 'dance of the mind', which transpires in altered states such as during ayahuasca inebriation. This mode of 'dance happens in an augmented realm beyond the physical brain and body though linked with them in some way.' (Moore 2018a, p.126). (Figure 2) Further research and experimentations are required in order to systematically explore how the aesthetics of VR may generate the apparitional environment of the tomb and its owner's motions within it plus the impact of the experience on the user.

\section{CONCLUSIONS: THE EVOLVING CULTURAL NARRATIVE THAT BINDS US ACROSS THE INFINITE}

Can we reconstruct the memory of a civilisation and people from the distant past? Can we ever know the dreams of the Egyptian tomb's owner who died 4000 years ago? In the 3D film Cave of Forgotten Dreams (2010) by Werner Herzog, he speculates that we can only perceive the individuals who made the painted images in the Chauvet Cave thirty thousand years ago through our current sensibilities and for as long as we recognise aspects of ourselves in the images that they made. Meaningful contact with a different culture occurs when we identify their humanity and creativity through a shared thread of awareness that binds us despite of and across the 'abyss of time' (Ibid). Despite our opposing ideologies, we seem to share with the ancient Egyptians a perpetual human quest that could be observed in the central themes that the tomb trigger. Our tombs are the new homes in which we house and explore our consciousness, i.e. our computers, VR headsets and AR glasses and screens, including the various gadgets and technologies through which we virtually extend and fragment our identities. Current tombs are also the vessels with which we aspire, perhaps similarly to the ancient Egyptians, to travel and live unbound in the Milky Way. The tomb and its owner are the blueprint of an evolving narrative, a shared racial memory that binds us with our ancient ancestors across the infinite. 
Additionally, the mythic narrative of the tomb and its dweller, although rooted in religious-magical system that is not in any way scientific, appeals, according to Maravelia (2003) to notions in modern astrophysics and scientific. For example, it has been noted that the Egyptian's conception of the pause of the cosmic time flow represents eternity and everlastingness, a state out of space and out of time. Today, such phenomenon is recognised in the event horizon of a black hole (Ibid.), where time halts and space ceases. Thus, the tomb could be addressed mythically and cosmologically or as a conceptual foundation for art and science lab for the study of space-time and the universe.

The aesthetic potentials of VR and AR conceptually resonate with the notion of the tomb as a mythic house of eternity, combining the earth and the heavens into a continuum of stars and dark matter. As Deren's scenario indicates, the encounter with the man in the tomb awakens forgotten memories, which in turn sets the visitor on a voyage in spacetime and consciousness.

\section{REFERENCES}

Ascott, R. (2003) Weaving the shamanic web: art and technoetics in the bio-telematic domain. In Ascott, R. \& Shanken, E. A. (eds.). Telematic Embrace Visionary Theories of Art, Technology and Consciousness, University of California Press, Berkley, Los Angeles and London.

Cave of Forgotten Dreams (2010). [film] Directed by Werner Herzog. Germany, France.

Clark, V.A., Hodson, M. and Neiman, C. (eds.) (1988) The Legend of Maya Deren: A Documentary Biography and Collected Works. New York: Anthology Film Archives, Film Culture.

Deren, M. (1946) An Anagram of Ideas on Art, Form and Film, NY: The Alicat Book Shop Press.

Geis, T. (2013) Death by amnesia: Maya Deren, Egypt, and "racial" memory. Dada/Surrealism, [ejournal] 19(1).

https://ir.uiowa.edu/dadasur/vol19/iss1/11/

(retrieved 2 February 2019).

Maravelia, A. A. (2003) Cosmic space and archetypal time: depictions of the sky-goddess nut in three royal tombs of the new kingdom and her relation to the milky way. Göttinger Miszellen, 197. 55-72.

Maravelia, A. (2017) Smart informatics \& Egyptology: a modern inter-disciplinary forum studying an ancient culture of pre-\& proto-scientific logistics \& intelligence. Proceedings of the Eighth International Conference on Intelligent Computing and Information Systems (ICICIS) Cairo, Egypt. 57, 2017, pp.11-20.

https://ieeexplore.ieee.org/xpl/mostRecentlssue.jsp ?punumber $=8250944$ (retrieved 2 February 2019).

Meshes of the Afternoon (1943). [film] Directed by Maya Deren. USA

Moore, L. (2018a) The shaman of cybernetic futures: art, ritual and transcendence in fields of the networked mind, Cybernetics \& Human Knowing, 25 (2-3). 119-141.

Moore, L. (2018b) Technoetic aesthetics of revelation and transcendence - the horse in the mind, paper presented at the Apocalypse in Art: The Creative Unveiling, CenSAMM Symposia Series Centre for the Critical Study of Apocalyptic and Millenarian Movements, Panacea Charitable Trust, Bedford, UK, 28-29 June, 2018. https://www.preprints.org/manuscript/201810.0040/ v1/ (retrieved 2 February 2019).

Nefertari: Journey to Eternity (2018) [VR] [360 film] Experius VR. USA: Curiosity Stream.

Simpson, W. K. and Ritner, R. K. (2003) The literature of ancient Egypt: an anthology of stories, instructions, stelae, autobiographies, and poetry. New Haven and London: Yale University Press.

The Met (2015) The Artist Project: Sarah sze. https://www.youtube.com/watch?v=pnmSk wzfnc (retrieved 2 February 2019).

The Tomb of Perneb at The Metropolitan Museum of Art (2011) [video] Directed and Produced by Christopher Noey https://www.metmuseum.org/metmedia/video/collec tions/egyptian/tomb-of-perneb (retrieved 2 February 2019).

Tombs and Monuments of Egypt (2018) [VR] [360 film] Experius VR. USA: Curiosity Stream.

Tucker, Michael. (1992) Dreaming with open eyes: the shamanic spirit in twentieth-century art and culture. London: Aquarian/Thorsons, Harper Collins Publishers.

Vosmeer, M., Schouten, B. (2014) Interactive cinema: engagement and interaction. International Conference on Interactive Digital Storytelling, Singapore, 3-6 November, 2014, Springer International Publishing Switzerland, pp.140-147. https://www.researchgate.net/publication/29030347 0 Interactive Cinema Engagement and Interactio $\underline{\text { n }}$ (retrieved 2 February 2019). 